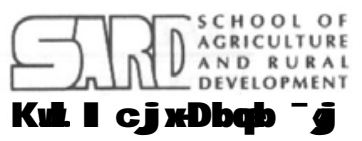

Available online at http:/ / www.banglajol.info/index.php/jard

\title{
Selection of Mungbean Variety for Rice-Wheat-Fallow Cropping System -A Participatory Research and Development (PR\&D) Approach
}

\author{
M. N. BARI ${ }^{1}$ \& M. R. ISLAM ${ }^{2 *}$ \\ Department of Agronomy, Bangabandhu Sheikh Mujibur Rahman Agricultural University, \\ Gazipur-1706, Bangladesh
}

\begin{abstract}
The study was conducted at three villages under Birganj upazilla of Dinajpur district to select suitable mungbean genotype to fit in the rice-wheat-fallow cropping system. Nine advanced mungbean genotypes and a check variety were tested in the farmers' fields through mother and baby trials managed by the farmers themselves. The mother trials were laid down in a radomized completely block design with three replications. Based on farmers' judgment regarding field performances and post-harvest evaluation on growth, field duration, seed yield, taste, cooking and milling quality, VC3960-88 appeared as the most preferred genotype. Farmers also preferred VC6153B-20P next to the above genotype. The baby trials conducted in thirty farmers' field reaffirmed that VC3960-88 was also the most preferred genotype. The performance of genotypes in baby trials and subsequent preference of the farmers signified the role of mother-baby trial approach towards selecting mungbean genotype by themselves.
\end{abstract}

Key words: Variety, mungbean, selection, cropping system, PR \& D approach.

\section{INTRODUCTION}

Rice-rice and rice-wheat are the two major cropping patterns widely practiced throughout Bangladesh. Practicing the rotations adding inadequate and disproportionate amount of fertilizers have been creating system productivity stagnation, nutrient and water imbalance, soil organic matter depletion (Zia et al., 1992). Conversely, the increasing demand for food necessitates further intensification of the crop productivity systems. The increase in cropping intensity or even sustaining the currently adopted cropping systems calls for inclusion of grain legumes for improving nutrition status of the people and maintaining soil health (Becker et al., 1995; Norman et al., 1984). The ameliorating effect of including legumes in cereal-based cropping systems has long been recognized, but because of low yield potentials and susceptibility to environmental stresses, legumes have generally declined in importance over time.

Mungbean (Vigna radiate L.) is an important crop for both human nutrition and enrichment of soil fertility (Norman et al., 1984). In recent years, the cultivation of summer mungbean has been expanded considerably to the south-western districts of Bangladesh. Possibility of growing mungbean in rice-rice or rice-wheat systems also exists in the northern districts. The expansion of mungbean cultivation in such non-traditional areas depends largely on its competitive ability with

*Corresponding author: Associate Professor, Department of Agronomy, BSMRAU, Gazipur 1706 E-mail: rafiarib@yahoo.com

(C) 2009 School of Agriculture and Rural Development, Bangladesh Open University, All rights reserved. 
other crops (Hamid, 1996) and adaptability over a wide range of environmental conditions (Popalghat et al., 2001). Among the environmental factors, high monsoon rain at the time of reproductive period causes enormous loss of both seed yield and seed quality of mungbean (Williams et al., 1995). The mungbean varieties those used in the existing cropping systems are low yielding, small seeded, longer duration with non-synchronous maturity (Sarkar et al., 1996). So, the development or selection of short duration mungbean genotype(s) with synchronous pod maturity might be the best option to increase systems productivity, improve soil health and increase nutrition and income of the farming communities in the northern districts of Bangladesh.

Participatory varietal selection (PVS) are farmer-centered varietal selection limited to testing of finished varieites. PVS tests varieties in farmers' field not on research stations where farmers evaluate multiple traits that are important to them and helps to increase on-farm varietal diversity, faster varietal replacement and rapid scaling up. Moreover, quality traits like milling percentage, cooking and keeping quality, taste, and market price can be assessed in PVS that are difficult or expensive to evaluate in conventional trials. All PVS use some form of mother and baby trials where mother trials are fewer in number than the baby trials to compare all of the test entries (Witcoimbe, 2005). Therefore, this study aims to select suitable mungbean variety(s) for the ricewheat-fallow cropping system with the contribution of participatory research and development (PR \& D) approach through PVS employing mother and baby trials with a view to increase system productivity by including food legumes in the cereal-based cropping systems in the north-western region of Bangladesh.

\section{MATERIALS AND Methods}

The study was carried out during April to July 2005 at three villages under Birganj upazila of Dinajpur district. Birgonj, comprising an area of $413 \mathrm{~km}^{2}$, is located at $25^{\circ} 48^{\prime}$ to $26^{\circ} 04^{\prime} \mathrm{N}$ latitude and $88^{\circ} 26^{\prime}$ to $88^{\circ} 40^{\prime} \mathrm{E}$ longitude. The study was conducted in the farmers' fields, organized and managed by the farmers themselves. Researchers shared the scientific information and facilitated farmers to experiment with advanced mungbean genotypes generated from the formal research system.

\section{Participatory assessment and diagnosis for farmers' situation}

A participatory approach to diagnosis and assessment was adopted to facilitate farmers to provide necessary information through the use of various participatory rural appraisal (PRA) methods and tools. A preliminary discussion was held with the different stakeholders including local leaders, union council representatives, leading farmers, and personnel from the Department of Agricultural Extension (DAE) to conduct the study smoothly. Thereafter, the leading farmers organized a focus group discussion (FGD) where the role of different participants and stakeholders was thoroughly discussed. Farmers made a social map of the villages where they located the trial plots. Farmers also prepared a seasonal activity calendar that included farmers' usual practices of cultivating crops in different growing seasons.

\section{Farmers' experimentation through mother-baby trials}

The study was commenced through mother and baby trials by incorporating mungbean genotypes. Mother trial (MT) was conducted in three farmers' fields previously selected in FGD. Participating farmers in MT did the layout of the experiment and performed all the crop management practices as per their own choice and the researchers facilitated to carry out all the activities. Unit plot size for MT was 4×3m. Ten mungbean genotypes viz. GK7, GK65, VC6173A, VC3960-88, VC6153B20G, VC6153B-20P, IPK2558-97, ML267, ML613, and BUmug2 (check variety) were the treatment variables that were included in a randomized complete block design with three replications. Each MT plot was considered as single replicate. The farmers were provided with seeds, fertilizers and other logistic supports. Seeds of the genotypes were sown on 7 April 2005. The crop was fertilized as per national recommendation for the study area (BARC, 1997). Baby trial (BT) for each genotype was carried out in thirty farmers' fields across the villages with 3 replications. Baby trial plot size was approximately $50 \mathrm{~m}^{2}$ and seeds were sown during 7-9 April 2005. Farmers assigned for baby trial grew mungbean through their own management practices. 


\section{Participatory monitoring and evaluation}

Participatory monitoring and evaluation involved joint monitoring and evaluation by the farmers, researchers and extension personnel. Farmers played the key and decisive role in assessing genotypic performance of mungbean during monitoring and evaluation by using their own observations, criteria and perceptions. For BT, farmers made their own assessment but their feedback was recorded by the researchers. The first joint follow-up visit was done at vegetative growth stage to evaluate the crop growth pattern. The second joint follow-up visit was done at maturity stage to identify preferred crop characters using matrix ranking. For each plant character, ten seeds were allotted for each genotype at a time and farmers were asked to put a set number of seeds they judged that genotype qualifies for that particular character and then moved to the second genotype for the same character. Farmers observed and evaluated the genotypes as per criteria outlined by them during the first FGD. At the same time, the BT farmers were also interviewed by using a household level questionnaire (HLQ).

\section{RESULTS AND Discussion}

Data obtained from mother trial were put to analysis of variance (ANOVA) and the means were separated by LSD test. The results are interpreted and discussed bellow:

\section{Crops and cropping systems in the study area}

The area of the three villages viz. Chakai, Bara Bochapukur and Damaikhetra is 1,135 ha comprising of $94.6 \%$ cultivable and $5.4 \%$ non-cultivable land. Cultivable land covers $0.6 \%$ single cropped, $48.4 \%$ double cropped and $51.0 \%$ triple cropped. The area is dominated by high land with sandy loam and loamy soils. Major crops are rice, wheat, maize, potato, summer and winter vegetables. Marginal farmers having an average land holding of $<0.15$ ha were dominating in the study area. The dominant cropping pattern is boro (winter) rice-fallow-transplanted aman (autumn) rice, followed by potato-maize-transplanted aman rice and wheat-fallow-transplanted aman rice. It might be mentioned that maize production has been increasing tremendously in the entire northern region of Bangladesh in recent years as a result of rapid growth of poultry sector where maize is an important ingredient of poultry feed. Therefore, a serious competition between maize and other crops has been growing.

\section{Seasonal activity pattern}

A seasonal activity calender was prepared by the farmers for the area where they showed four major rice-based cropping patterns (Figure 1). Aman rice generally tranplanted during the mid June to mid July and harvested within 2nd week of November. During this period, high labour requirements bring the farmers to be very busy with the cultivation of the crop. Thereafter, some farmers have options for cultivating potato or vegetables followed by maize. After harvesting maize, farmers remain idle for about one month and wait for cultivating aman rice for the next season. However, the farmers those cultivate boro after aman rice have to wait a long preriod for the next season as this gap period (Mid April to June) is not sufficient to grow any crop. Only the farmers who cultivate wheat after aman rice find a longer gap period between mid March to June that offers the farmers to include mungbean in fallow period between rice and wheat.

Figure 1. Seasonal activity calendar showing the four major cropping patterns in the study area

\begin{tabular}{|c|c|c|c|c|c|c|c|c|c|c|}
\hline Jan & Mar & Apr & May & Jun & Jul & Aug & Sep & Oct & Nov & Dec \\
\hline \multicolumn{2}{|l|}{ Wheat } & \multicolumn{3}{|c|}{ Fallow } & \multicolumn{4}{|c|}{ Transplanted aman rice } & \multicolumn{2}{|c|}{ Wheat } \\
\hline Potato & \multicolumn{3}{|c|}{ Maize } & Fallow & \multicolumn{4}{|c|}{ Transplanted aman rice } & \multicolumn{2}{|c|}{ Potato } \\
\hline Vegetables & \multicolumn{3}{|c|}{ Maize } & Fallow & \multicolumn{4}{|c|}{ Transplanted aman rice } & \multicolumn{2}{|c|}{ Vegetables } \\
\hline \multicolumn{2}{|c|}{ Boro rice } & \multicolumn{3}{|c|}{ Fallow } & \multicolumn{4}{|c|}{ Transplanted aman rice } & \multicolumn{2}{|c|}{ Boro rice } \\
\hline
\end{tabular}




\section{Evaluation of mungbean genotypes in mother trial}

Participating farmers evaluated mungbean genotypes in two broad aspects i.e. field performance and post-harvest quality. Field performance was evaluated in FGD during maturity stage. The matrix score showed that except seedling emergence and insect-pest resistance characters, days to first flowering, days to $50 \%$ flowering, maturity duration, plant height, plant growth, lodging resistance, pod size and uniformity significantly differed among the genotypes (Table 1). Farmers mostly preferred BUmug2 (check variety) for short maturity duration as well as short stature and lodging resistance characters. Farmers also preferred VC3960-88 for better size and uniformity of pods. They also showed interest on GK7, VC6153B-20P, VC6153B-20G, GK65, VC6173A, however, had a fair choice of ML613 and ML267 for late maturing, long stature and lodging susceptible characteristics. Early maturing genotypes produced bolder seeds compared to late maturing ones and were mostly preferred by the farmers. Sandhu et al. (1988) also found bolder seeds in early maturing mungbean genotype.

Table 1. Field performance of mungbean genotypes as evaluated by the farmers during maturity

\begin{tabular}{lccccccccc}
\hline $\begin{array}{c}\text { Variety/ } \\
\text { Line }\end{array}$ & $\begin{array}{c}\text { Seedling } \\
\text { emergence flowering }\end{array}$ & $\begin{array}{c}\text { First } \\
\text { flowering }\end{array}$ & $\begin{array}{c}\text { Maturity } \\
\text { duration }\end{array}$ & $\begin{array}{c}\text { Plant } \\
\text { height }\end{array}$ & $\begin{array}{c}\text { Plant } \\
\text { growth }\end{array}$ & $\begin{array}{c}\text { Lodging } \\
\text { resistance }\end{array}$ & $\begin{array}{c}\text { Insect \& } \\
\text { pest } \\
\text { resistance uniformity }\end{array}$ & $\begin{array}{c}\text { Pod size } \\
\text { and }\end{array}$ \\
\hline GK7 & 9.0 & 9.3 & 8.3 & 7.7 & 7.7 & 7.7 & 7.0 & 7.3 & 6.3 \\
GK65 & 9.0 & 8.7 & 7.7 & 8.0 & 7.0 & 6.7 & 6.7 & 6.7 & 6.0 \\
VC6173 A & 8.3 & 8.0 & 6.0 & 7.3 & 7.0 & 7.0 & 6.3 & 7.7 & 7.0 \\
VC3960-88 & 9.0 & 8.0 & 7.7 & 8.3 & 8.0 & 8.0 & 7.7 & 8.7 & 9.0 \\
VC6153B-20G & 8.0 & 7.7 & 6.3 & 7.3 & 7.0 & 8.3 & 8.3 & 8.0 & 7.7 \\
VC6153B-20P & 9.0 & 7.7 & 7.0 & 6.7 & 7.3 & 7.7 & 7.7 & 7.3 & 7.7 \\
IPK2558-97 & 9.3 & 6.0 & 5.3 & 3.7 & 4.7 & 6.0 & 5.0 & 6.0 & 4.7 \\
ML267 & 9.7 & 5.0 & 3.7 & 2.7 & 4.0 & 7.3 & 5.0 & 7.7 & 4.3 \\
ML613 & 9.3 & 7.0 & 3.7 & 2.7 & 3.3 & 4.0 & 5.0 & 7.3 & 5.0 \\
BUmug 2 & 7.3 & 10.0 & 9.3 & 9.3 & 9.3 & 9.3 & 10.0 & 8.0 & 8.7 \\
\hline LSD at 0.01 & $\mathrm{NS}^{*}$ & 1.66 & 1.56 & 1.79 & 2.29 & 1.60 & 1.64 & $\mathrm{NS}$ & 1.20 \\
\hline CV (\%) & 8.9 & 13.0 & 14.0 & 16.4 & 20.4 & 13.5 & 13.9 & 14.7 & 10.5 \\
\hline
\end{tabular}

*non significant

Mean matrix scores during harvest comprising of growth and maturity duration showed that genotype BUmug2 still stands in first choice followed by VC3960-88 (Table 2). The farmers perception in choosing the genotypes varied spectacularly over the growing period. When seed yield results add-on growth and maturity duration, their chioce shifted to a large extent showing equal prefereance on BUmug2 and VC3960-88 (Table 4). Although the seed yield of ML613 resembled to VC3960-88, the latter was quiet the most wanted genotype for being better growth and shorter duration. However, genotype VC6153B-20P was the third choice of the farmers considering all the three charcters evaluated during harvest.

Table 2. Performance of mungbean genotypes as evaluated by the farmers during harvest

\begin{tabular}{lccc}
\hline Variety/Line & Overall growth & Maturity & Yield \\
\hline GK7 & 7.7 & 8.3 & 7.3 \\
GK65 & 8.0 & 8.3 & 7.3 \\
VC6173A & 7.7 & 7.3 & 7.0 \\
VC3960-88 & 9.3 & 8.7 & 9.3 \\
VC6153B-20G & 8.0 & 7.3 & 7.3 \\
VC6153B-20P & 8.0 & 8.0 & 9.0 \\
IPK2558-97 & 4.3 & 5.3 & 6.3 \\
ML267 & 4.0 & 5.0 & 7.0 \\
ML613 & 3.3 & 3.7 & 9.3 \\
BUmug2 & 9.7 & 10.0 & 7.7 \\
\hline LSD 0.05 & 1.42 & 0.58 & 1.41 \\
\hline CV $(\%)$ & 11.86 & 4.71 & 10.60 \\
\hline
\end{tabular}


Farmers' choice in grain size, shape and color highly varied (Table 3). Based on the grain qualities, VC3960-88 was the single most preferred genotype. In contrast, the farmers had no choice on ML267. The variation in their choice narrowed down in subsequent evaluation on taste, cooking and milling quality of grains. However, when grain size, shape and color were considered along with taste, cooking and milling quality of grain, a remarkable change in farmers' choice was noticed in selecting genotypes. Here, the genotype VC3960-88 was still the most preferred genotype. However, ML613 ranked the second position in terms of post-harvest qualities being followed by VC6153B-20P. Surprisingly, the check variety BUmug2 was shifted to eighth position.

Table 3. Post-harvest evaluation of mungbean genotypes by the farmers

\begin{tabular}{lccccc}
\hline Variety/Line & $\begin{array}{c}\text { Grain size } \\
\text { and shape }\end{array}$ & $\begin{array}{c}\text { Grain } \\
\text { colour* }\end{array}$ & Taste & $\begin{array}{c}\text { Cooking } \\
\text { quality }\end{array}$ & $\begin{array}{c}\text { Milling } \\
\text { quality }\end{array}$ \\
\hline GK7 & 5 & 4 & 8.7 & 10.0 & 8.3 \\
GK65 & 6 & 6 & 7.7 & 10.0 & 7.7 \\
VC6173A & 0 & 1 & 8.7 & 10.0 & 8.7 \\
VC3960-88 & 9 & 7 & 9.0 & 10.0 & 9.0 \\
VC6153B-20G & 3 & 4 & 9.3 & 9.7 & 9.0 \\
VC6153B-20P & 8 & 4 & 8.7 & 9.0 & 10.0 \\
IPK2558-97 & 3 & 7 & 8.0 & 9.0 & 8.3 \\
ML267 & 0 & 0 & 8.7 & 9.7 & 9.0 \\
ML613 & 7 & 7 & 8.0 & 9.7 & 9.0 \\
BUmug2 & 3 & 4 & 8.7 & 10.0 & 8.7 \\
\hline LSD (0.05) & & & 1.02 & 0.54 & 0.85 \\
\hline CV (\%) & & & 6.99 & 3.26 & 5.68 \\
\hline
\end{tabular}

* Scoring was done by pair wise ranking

The study also made the quantitative evaluation of the yield performance of the genotypes. This was compared with the successive evaluations made by the farmers and illustrated in Table 4. The genotype ML613 gave the highest yield followed by VC3960-88 and ML267, whereas, check variety BUmug2 yielded very poorly. Farmers' choice in post-harvest evaluation was interesting where the two long duration lines ML613 and ML267 ranked as seven and ninth, respectively but VC3960-88 was considered as most preferred genotype. Here check variety BUmug2 has been given second most priority although it has given ninth position in terms of yield. Results indicated that farmers put choice for uniform growth, shorter duration as well as higher seed yield, which fully matched with the performance of VC3960-88 rather than BUmug2. Farmers also preferred ML613 as a good yielder, however, under conditions that it would not be affected by monsoon rain at maturity stage.

Table 4. Agronomic and overall performances of mungbean genotypes

\begin{tabular}{|c|c|c|c|c|c|c|}
\hline Variety/Line & $\begin{array}{c}\text { Yield under } \\
\text { mother trial } \\
(\mathrm{kg} / \mathrm{ha})\end{array}$ & $\begin{array}{c}\text { Yield under } \\
\text { baby trial } \\
\text { (kg/ha) }\end{array}$ & $\begin{array}{c}\text { Performance } \\
\text { Field } \\
\text { performance }\end{array}$ & $\begin{array}{c}\text { as evaluated } \\
\text { Performance } \\
\text { at harvest }\end{array}$ & $\begin{array}{l}\text { by the farmers } \\
\text { Post harvest } \\
\text { performance }\end{array}$ & $\begin{array}{c}\text { Overall } \\
\text { performance }\end{array}$ \\
\hline GK7 & 736 (VII) & $350(V)$ & 7.8 & 7.8 & 7.2 & 7.6 (IV) \\
\hline GK65 & $833(\mathrm{VI})$ & 450 (II) & 7.4 & 7.9 & 7.5 & 7.6 (IV) \\
\hline VC6173A & 861 (IV) & 433 (III) & 7.2 & 7.3 & 5.7 & $6.7(\mathrm{VI})$ \\
\hline VC3960-88 & 930 (II) & $650(\mathrm{I})$ & 8.3 & 9.1 & 8.8 & $8.7(I)$ \\
\hline VC6153B-20G & $851(\mathrm{~V})$ & 213 (VIII) & 7.6 & 7.5 & 7.0 & $7.4(\mathrm{~V})$ \\
\hline VC6153B-20P & 896 (III) & 383 (IV) & 7.6 & 8.3 & 7.9 & 7.9 (III) \\
\hline IPK2558-97 & 722 (VIII) & 250 (VII) & 5.6 & 5.3 & 7.1 & 6.0 (VIII) \\
\hline ML267 & 930 (II) & $100(X)$ & 5.5 & 5.3 & 5.5 & $5.4(\mathrm{IX})$ \\
\hline ML613 & $944(\mathrm{I})$ & $300(\mathrm{VI})$ & 5.3 & 5.4 & 8.1 & 6.3 (VII) \\
\hline BUmug2 & 708 (IX) & 200 (IX) & 9.0 & 9.1 & 6.9 & 8.3 (II) \\
\hline
\end{tabular}




\section{Evaluation of mungbean genotypes through baby trial}

Seedling emergence was adequate and vegetative growth of plants was satisfactory in almost all baby trial plots. Multiple pod harvests were done by most of the farmers. About $35 \%$ farmers opined that their genotypes were early maturing and that of $30 \%$ late maturing (Figure 2). Pods of the earliest genotype started to mature at 52 days but late maturing genotype took 85 days to mature. However, days to flowering and maturity were comparatively shorter in BUmug2, GK65, GK7, VC3966-88, VC6173A and longer in ML267, ML613 and IPK2558-9 and others were medium duration. The results were somehow conclusive because the genotypes showed almost similar growth duration in the MT.

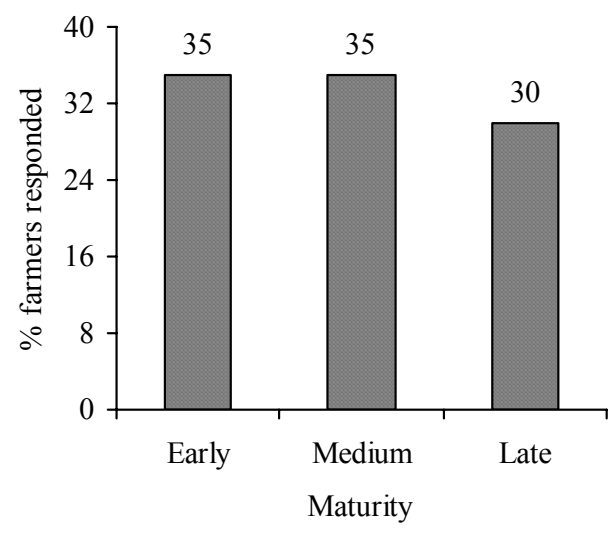

Figure 2. Maturity duration of mungbean as respondent by baby trial farmers

Around half of the BT farmers harvested a good yield from their trial plots (Figure 3). Other farmers obtained medium or poor yield. However, there was an indication that farmers were satisfied mostly with their own genotypes or seeks for other genotype which could be high yielder and fit well in their cropping systems. Quantitative yield results of the genotypes under baby trial have been shown in Table 4. The highest yield was observed in VC3960-88 $\left(650 \mathrm{~kg} \mathrm{ha}^{-1}\right)$ followed by GK65, VC6163A, VC6153B-20P and GK7 and these were found as medium yielder (350-450 kg $\left.\mathrm{ha}^{-1}\right)$. The rest were poor yielder $\left(100-300 \mathrm{~kg} \mathrm{ha}^{-1}\right)$. Grain color, grain size and shape of the respective genotype was highly preferred by the farmers. Dal quality (appearance) and milling recovery of all the genotypes were good. Cooking time was short and quality of cooked dal soup and taste were good enough.

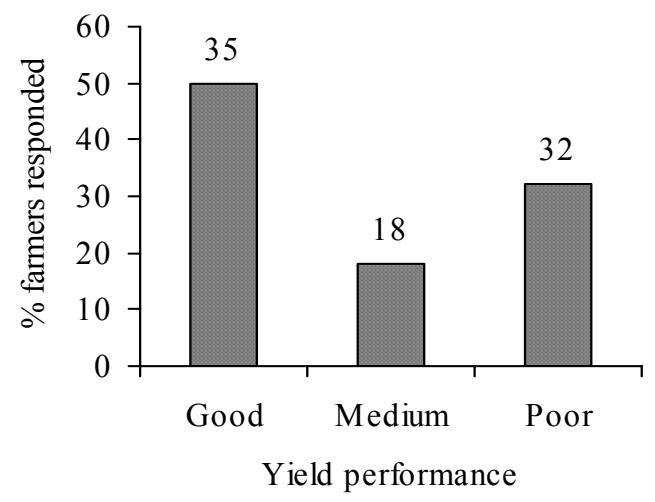

Figure 3. Yield performance of mungbean as responded by baby trial farmers 
The BT revealed that VC3960-88 appeared as the single most preferred genotype having the highest yield, relatively shorter field duration, and uniform and bold seeds. Farmers showed interest to grow VC3960-88 in the next year. Being short duration and having a reasonable yield, GK7, GK65 and VC6173A were also preferred by the respective farmers. Farmers also showed willingness to grow VC6153B-20G during the next year if seeds of other suitable genotype would not be available. However, farmers were not interested to continue mungbean cultivation with the genotype IPK2558-97 that produced enough dry matter with longer field duration but lesser grain yield. Even high yielder but late maturing ML267 and ML613 also failed to attract the growers. In contrast, the short statured and short field duration variety BUmug2 created interest among the farmers to grow, but could not appear as a promising because of its poor yield performance under prevailing conditions.

\section{CONCLUSION}

Based on the data and findings of the present study, the following concluding remarks could be made:

- Farmers successfully experimented with the mungbean genotypes through participatory manner where they were able to select mungbean genotypes to suit their needs.

- Majority of the mungbean genotypes were found to fit well in the existing rice-wheat-fallow cropping systems.

- Mungbean genotype VC3960-88 appeared as the most preferred variety due to its shorter duration, higher yield, uniform seed size, and better taste, cooking and milling quality.

- Farmers also showed interest on long duration genotype ML613 for its high yield potential. However, they also expressed concern regarding its long field duration which could be prone to monsoon rain at maturity stage.

- Considerable awareness as well as enthusiasm has been created among the farmers of the study area as well as neighboring areas regarding the easy cultivation process of mungbean and its easy adjustment in the fallow period after the harvest of wheat.

- Satisfactory performance of the mungbean genotypes has also created interest among the DAE personnel since they failed to popularize this crop in the region after repeated failure of formal demonstration trials.

\section{RECOMMENDATIONS}

Considering the above facts and findings, the following recommendations might be put forward for consideration at policy level:

- The mungbean genotypes tested in the present study should be put under multi-location trials in the neighboring villages and areas to reach more precise conclusion as well as to enhance scaling up process.

- Study on the effect of inclusion of mungbean on the succeeding crops leading to assess the productivity of the whole system might be essential before reaching general conclusion.

- Detailed on-farm level study on the impact of maize cultivation on farm income, systems productivity as well as soil health should be conducted due to high nutrient mining ability of maize.

- Collaborative program comprising of GO and NGOs should be undertaken to popularize mungbean cultivation in the entire region. 


\section{LiTERATURE CiTED}

BARC. 1997. Fertilizer Recommendation Guide. Bangladesh Agricultural Research Council, Farmgate, Dhaka, Bangladesh.

Becker, M., Ladha, J. K. and Ali, M. 1995. Green Manure Technology: Potential usage, limitation: a case study for low land rice. Plant and Soil 174, 181-194.

Hamid, A. 1996. Growth and yield performance of mungbean (Vigna radiata L.) at a mid range of population densities. In "Recent Advances in Mungbean Research" (A. N. Asthana and K.D. Hwan, Eds.), Indian Society of Pulse Research, IIPR, Kanpur, India. pp. 92-100.

Norman, M. Z. T., Pearson, C. J. and Searle, P. G. E. 1984. The Ecology of Tropical Crops. Comb. Univ. Press.

Popalghat, G. R., Patil, J. U., Deshmukh, R. B. and Mhase, L. B. 2001. Genotype and environment interaction for seed yield and seed quality parameters in chickpea. Legume Research $\mathbf{2 4 , 2 4 8 -}$ 251.

Sandhu, T. S., Singh, K. and Singh, B. 1988. Mungbean germplasm resources: Evaluation and utilization. pp. 29-34. In Mungbean, Proceedings of Second International Symposium. AVRDC, Shanhua, Taiwan.

Sarker, A., Rahman, M. M,. Malek, M. A., Miah, A. A. and Siddique, A. R. 1996. Performance of exotic mungbean genotypes in Bangladesh. In "Recent Advances in Mungbean Research" (A.N. Asthana and K.D. Hwan (Eds), Indian Society of Pulse Research, IIPR, Kanpur, India. pp. 79-82.

Williams, R. W., Lawn R. J., Imrie B. C. and. Byth, D. E. 1995. Studies on weather damage in mungbean. In Effect of weathering on seed quality and viability. Australian J Agril Res 46, 887900.

Witcombe, J. R. 2005. Participatory varietal selection and participatory plant breeding: the last 10 years. In "Participatory Research and Development for Sustainable Agriculture and Natural Resource Management: A Sourcebook" (J. Gonsalves, T. Becker, A. Braun, D. Campilan, H. De Chavez, E. Fajber, M. Kapiriri, J. Rivaca-Caminade and R. Vernooy, Eds), CIP-UPWARD and IDRC.

Zia, M. S. R., Gill M. A. and Aslam, M. 1992. Fertilizer management in rice-wheat system. Progressive Farming 12, 14-18. 